\title{
Cycloexpansamines A and B: spiroindolinone alkaloids from a marine isolate of Penicillium sp. (SF-5292)
}

\author{
Chiwook Lee ${ }^{1,2}$, Jae Hak Sohn' ${ }^{2}$, Jae-Hyuk Jang ${ }^{3}$, Jong Seog $\mathrm{Ahn}^{3}$, Hyuncheol Oh${ }^{1}$, Jonas Baltrusaitis ${ }^{4}$, \\ In Hyun Hwang ${ }^{5}$ and James B Gloer ${ }^{5}$
}

The Journal of Antibiotics (2015) 68, 715-718; doi:10.1038/ja.2015.56; published online 13 May 2015

\begin{abstract}
Marine microorganisms are recognized as an important source of structurally diverse bioactive secondary metabolites. ${ }^{1,2}$ Particularly, secondary metabolites from marine fungal isolates have attracted significant interest, as many of them provide unique structural features and interesting biological properties. ${ }^{2-4}$ In our search for new metabolites from marine-derived fungi, we recently reported the isolation of an anti-inflammatory metabolite named penicillinolide A from extracts obtained from cultures of a marine-derived isolate of Penicillium sp. (SF-5292). ${ }^{5}$ As part of our continuing efforts to explore the chemistry of this isolate, studies of extracts obtained from largerscale cultures of the fungus were undertaken. From this investigation, two minor metabolites, cycloexpansamines A (1) and B (2) were isolated (Figure 1) in addition to previously encountered penicillinolide A.
\end{abstract}

The fungal strain was cultured on 80 petri-dish plates $(90 \mathrm{~mm})$, each containing $20 \mathrm{ml}$ of potato dextrose agar media $(0.4 \%(\mathrm{w} / \mathrm{v})$ potato starch, $2 \%(\mathrm{w} / \mathrm{v})$ dextrose, $3 \%(\mathrm{w} / \mathrm{v}) \mathrm{NaCl}, 1.5 \%(\mathrm{w} / \mathrm{v})$ agar). Plates were individually inoculated with $2-\mathrm{ml}$ seed cultures of the fungal strain. Plate cultures were incubated at $25^{\circ} \mathrm{C}$ for a period of 14 days. Extraction of the agar media with EtOAc $(2 \times 500 \mathrm{ml})$ provided an organic phase, which was then concentrated in vacuo to yield $1.9 \mathrm{~g}$ of an extract. The EtOAc extract was subjected to $\mathrm{C}_{18}$ flash column chromatography $(5 \times 40 \mathrm{~cm})$, eluting with a stepwise gradient of $20,40,60,80$ and $100 \%$ (v/v) $\mathrm{MeOH}$ in $\mathrm{H}_{2} \mathrm{O}$ (500 ml each). The fractions eluted at $80 \% \mathrm{MeOH}(418 \mathrm{mg})$ were purified by semipreparative reversed-phase HPLC eluting with a gradient from 40 to $100 \% \mathrm{MeOH}$ in $\mathrm{H}_{2} \mathrm{O}$ ( $0.1 \%$ formic acid) over $56 \mathrm{~min}$ to yield compound 1 (10.2 $\left.\mathrm{mg}, t_{R}=15.9 \mathrm{~min}\right)$. The fraction collected between 17 and $18 \mathrm{~min}$ in the above HPLC step was then subjected to further HPLC, eluting with a gradient from 40 to $65 \% \mathrm{MeOH}$ in $\mathrm{H}_{2} \mathrm{O}(0.1 \%$ formic acid) over $40 \mathrm{~min}$ to yield compound 2 ( $\left.1.4 \mathrm{mg}, t_{R}=27.6 \mathrm{~min}\right)$.

Cycloexpansamine A (1) gave an $[\mathrm{M}+\mathrm{H}]^{+}$ion at $\mathrm{m} / \mathrm{z} 450.2380$ in the HRESI mass spectrum, indicating a molecular formula of $\mathrm{C}_{26} \mathrm{H}_{31} \mathrm{~N}_{3} \mathrm{O}_{4}$, which was fully supported by the ${ }^{1} \mathrm{H}$ and ${ }^{13} \mathrm{C}$ NMR data (Table 1). Analysis of its ${ }^{13} \mathrm{C}$ NMR and DEPT spectra revealed the presence of four methyl groups, two $\mathrm{sp}^{2}$ methines, one $\mathrm{sp}^{3}$ methine and seven $\mathrm{sp}^{3}$ methylene units (including one bound to a heteroatom), as well as three carbonyl and four non-protonated aromatic/ olefinic carbons. Because only six out of the 13 unsaturations were accounted for by these units, cycloexpansamine A (1) was required to contain seven rings. The structure of 1 could be fully defined by comprehensive analysis of $1 \mathrm{D}$ and $2 \mathrm{D}$ NMR data, including ${ }^{1} \mathrm{H}$, ${ }^{13} \mathrm{C}$ NMR, COSY, HSQC and HMBC experiments (Table 1). A literature search indicated that the planar structure of 1 was proposed for a metabolite of another unidentified Penicillium sp. in a recent US patent. ${ }^{6}$ However, ${ }^{1} \mathrm{H}$ and ${ }^{13} \mathrm{C}$ NMR position assignments were not provided, nor were HRMS data and stereochemical assignments. Therefore, our attention turned into the comprehensive structure determination of $\mathbf{1}$, including absolute configuration.

The relative configuration of compound $\mathbf{1}$ was determined by analysis of NOESY data (Figure 2). Since 1 consists of separated fused ring systems connected at a spiro-carbon atom, the two ring systems are virtually perpendicular to one another. NOESY correlations of $\mathrm{H}-10$ with $\mathrm{H}_{3}-28$ and $\mathrm{H}-23 \beta$, and of $\mathrm{H}-23 \beta$ with $\mathrm{NH}-25$ indicated that one of the methyl groups at $\mathrm{C}-13$, the $\mathrm{C} 1-\mathrm{C} 11$ bond and the amide group (C-24) are $\beta$-oriented. This was also supported by the observation of NOESY correlations of $\mathrm{H}_{3}-28$ with $\mathrm{H}-23 \beta$. On the other hand, NOESY correlations of $\mathrm{H}_{3}-29$ with $\mathrm{H}-14$; of $\mathrm{H}-14$ with $\mathrm{H}-21 \alpha$ and $\mathrm{H}-23 \alpha$; and of $\mathrm{H}-21 \alpha$ with $\mathrm{H}-23 \alpha$ suggested $\alpha$-orientations for $\mathrm{H}-14, \mathrm{H}-21 \alpha, \mathrm{H}-23 \alpha$ and $\mathrm{H}_{3}-29$. Therefore, the relative configuration of 1 was suggested as shown.

The absolute configuration of $\mathbf{1}$ was proposed by analysis of its electronic circular dichroism (ECD) spectrum and by comparison to its calculated spectrum (Supplementary Information). The Cotton effect at $250-350 \mathrm{~nm}$ is considered to be related to the configuration at the spirogenic center in ECD spectra of spiro-oxindole alkaloids. ${ }^{7-9}$ The ECD spectrum of $\mathbf{1}$ (Supplementary Figure S1) showed a positive Cotton effect in the spiro-oxindole absorbance region around $270 \mathrm{~nm}$, which suggested the $1 S$ configuration for $\mathbf{1}$, and this assignment is in agreement with the configurations previously established for related

${ }^{1}$ Department of Pharmacy, College of Pharmacy, Wonkwang University, Iksan, Korea; ${ }^{2}$ Department of Bio-food Materials, College of Medical and Life Sciences, Silla University, Busan, Korea; ${ }^{3}$ Chemical Biology Research Center, Korea Research Institute of Bioscience and Biotechnology (KRIBB), Cheongwon, Korea; ${ }^{4}$ PhotoCatalytic Synthesis Group, University of Twente, Enschede, The Netherlands and ${ }^{5}$ Department of Chemistry, University of lowa, lowa City, IA, USA 


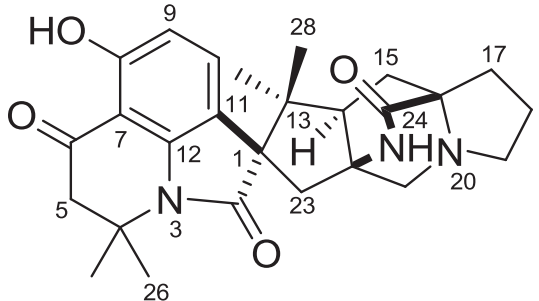

1

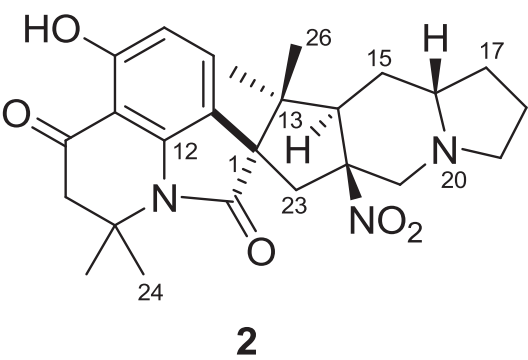

2

Figure 1 Structures of cycloexpansamines A (1) and B (2).

Table 1 NMR spectroscopic data for cycloexpansamine A (1) in pyridine- $d_{5}$

\begin{tabular}{|c|c|c|c|c|}
\hline No. & $\delta_{C}{ }^{\mathrm{a}}$ & $\delta_{H}$, mult. $(J \text { in } H z)^{b}$ & Key NOESYC & $H M B C(H \rightarrow C \#)$ \\
\hline 1 & 64.9 & - & - & \\
\hline 2 & 183.0 & - & - & - \\
\hline 4 & 57.2 & - & - & - \\
\hline \multirow[t]{2}{*}{5} & 51.6 & 2.67, d (16.5) & - & \\
\hline & & 2.99, d (16.5) & - & $4,6,7,26,27$ \\
\hline 6 & 197.5 & - & - & - \\
\hline 7 & 104.9 & - & - & - \\
\hline 8 & 160.0 & - & - & - \\
\hline 9 & 108.8 & $6.60, d(8.4)$ & - & $6,7,8,11$ \\
\hline 10 & 134.3 & $7.26, \mathrm{~d}(8.4)$ & $\mathrm{H}-23 \beta, \mathrm{H}-28$ & $1,8,12$ \\
\hline 11 & 119.2 & - & - & - \\
\hline 12 & 147.9 & - & - & - \\
\hline 13 & 47.8 & - & - & - \\
\hline 14 & 49.3 & $3.39, \mathrm{t}(8.4)$ & $\begin{array}{c}H-15 \alpha, H-21 \alpha \\
H-29\end{array}$ & $\begin{array}{c}13,15,21,22,28 \\
29\end{array}$ \\
\hline \multirow[t]{2}{*}{15} & 32.7 & 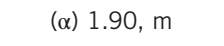 & $\mathrm{H}-14$ & $14,16,17,22,24$ \\
\hline & & ( $\beta$ ) $1.78, \mathrm{~m}$ & $\mathrm{H}-28$ & - \\
\hline 16 & 67.3 & - & - & - \\
\hline \multirow[t]{2}{*}{17} & 27.8 & $3.01, \mathrm{~m}$ & - & 16,24 \\
\hline & & $1.51, \mathrm{~m}$ & - & $15,16,24$ \\
\hline 18 & 24.9 & $1.86-1.99, \mathrm{~m}$ & - & 17,19 \\
\hline \multirow[t]{2}{*}{19} & 54.0 & $3.06, \mathrm{~m}$ & - & 16 \\
\hline & & $\begin{array}{c}2.28, \mathrm{dd}(17.2 \\
8.4)\end{array}$ & - & 18,21 \\
\hline \multirow[t]{2}{*}{21} & 64.0 & ( $\alpha) 3.75, d(8.4)$ & $\mathrm{H}-23 \alpha$ & $14,15,16,22,23$ \\
\hline & & ( $\beta$ ) $2.49, \mathrm{~d}(8.4)$ & - & $14,19,22$ \\
\hline 22 & 63.5 & - & - & - \\
\hline \multirow[t]{2}{*}{23} & 40.4 & ( $\beta$ ) 2.47, d (15.0) & $\mathrm{H}-10, \mathrm{H}-25, \mathrm{H}-28$ & 2,11 \\
\hline & & 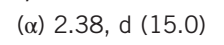 & $H-21 \alpha$ & $1,2,13,21$ \\
\hline 24 & 174.0 & - & - & - \\
\hline 25 & - & $9.06, \mathrm{~s}$ & $\mathrm{H}-23 \beta$ & $14,16,22,23$ \\
\hline 26 & 23.9 & $1.43, \mathrm{~s}$ & - & $4,5,27$ \\
\hline 27 & 26.8 & $1.77, \mathrm{~s}$ & - & $4,5,26$ \\
\hline 28 & 21.3 & $1.12, \mathrm{~s}$ & $\mathrm{H}-10, \mathrm{H}-15 \beta, \mathrm{H}-23 \beta$ & $1,13,14,29$ \\
\hline 29 & 23.3 & $0.84, \mathrm{~s}$ & $\mathrm{H}-14$ & $1,13,14,28$ \\
\hline
\end{tabular}

aRecorded at $100 \mathrm{MHz}$.

bRecorded at $400 \mathrm{MHz}$

'Recorded at $600 \mathrm{MHz}$

compounds containing spiro-oxindole units, such as synthetic ent-(+)-paraherquamide $\mathrm{B}^{10}$ and (+)-versicolamide $\mathrm{B}^{7}$ In an effort to provide independent support for this assignment, the ECD spectrum of an energy-minimized conformer of 1 (generated using Spartan '10, Wavefunction, Inc., CA, USA) was simulated using timedependent density functional theory (TDDFT) calculations, and compared with the experimental data for 1 . The experimental ECD spectrum of 1 matched closely with the calculated ECD spectrum. Therefore, on the basis of both empirical considerations and TDDFT calculations, the absolute configuration of $\mathbf{1}$ was assigned as shown.

Cycloexpansamine B (2) was assigned the molecular formula $\mathrm{C}_{25} \mathrm{H}_{31} \mathrm{~N}_{3} \mathrm{O}_{5}$ (11 unsaturations) on the basis of high-resolution electrospray ionisation mass spectrometry (HRESIMS) and NMR data (Table 2). Analysis of its ${ }^{13} \mathrm{C}$ NMR and DEPT spectra revealed the presence of four methyl groups, two $\mathrm{sp}^{2}$ methines, two $\mathrm{sp}^{3}$ methines and seven $\mathrm{sp}^{3}$ methylene units, as well as two carbonyl and four non-protonated aromatic or olefinic $\mathrm{sp}^{2}$ carbons. Analysis of the ${ }^{1} \mathrm{H}$ and ${ }^{13} \mathrm{C}$ NMR data suggested that the overall structure of 2 is similar to that of $\mathbf{1}$. The main difference was evident in the absence of one carbonyl signal in the ${ }^{13} \mathrm{C}$ NMR spectrum, and changes in the chemical shifts corresponding to the $\mathrm{C}-15, \mathrm{C}-16 \quad\left(\mathrm{sp}^{3}\right.$ methine instead of $\mathrm{sp}^{3}$ quaternary carbon), and C-22 positions of 1 . These observations suggested that 2 differs from 1 by the absence of the bridged amide ring system and associated structural modification around this functionality. The planar structure of $\mathbf{2}$ was finally inferred by considering this information together with a comprehensive analysis of 2D NMR data as well as close comparisons of the data with those reported for related metabolites, cyclopiamines ${ }^{11,12}$ and citrinalins. ${ }^{13}$

The relative configuration of $\mathbf{2}$ was determined by analysis of the NOESY spectrum (Figure 2) and by analogy to cycloexpansamine A (1). As in the case of 1 , NOESY correlations of $\mathrm{H}_{3}-26$ with $\mathrm{H}-10$ and $\mathrm{H}-23 \beta$ indicated that one of the methyl groups at $\mathrm{C}-13$, the $\mathrm{C} 1-\mathrm{C} 11$ bond and $\mathrm{H}-23 \beta$ were $\beta$-oriented. On the other hand, NOESY correlations of $\mathrm{H}-14$ with $\mathrm{H}-17 \alpha, \mathrm{H}_{3}-27$ and $\mathrm{H}-21 \alpha$ suggested $\alpha$-orientations for $\mathrm{H}-14, \mathrm{H}-17 \alpha$ and $\mathrm{H}-21 \alpha$. This assignment in turn suggested $\beta$-orientation for the nitro group at C-22. Finally, NOESY correlations of $\mathrm{H}-15 \beta$ with $\mathrm{H}-16$, and of $\mathrm{H}-15 \alpha$ with $\mathrm{H}-14, \mathrm{H}-17 \alpha$ and $\mathrm{H}_{3}-27$ suggested $\beta$-orientation of $\mathrm{H}-16$. Therefore, the relative configuration of $\mathbf{2}$ was proposed as shown. In addition, by analogy to the recently proposed biogenesis of nitro group containing prenylated indole alkaloids from bicyclo[2.2.2] diazaoctane-containing metabolites (discussed below), the absolute configuration of $\mathbf{2}$ was proposed to be analogous to that of $\mathbf{1}$.

Cycloexpansamine A (1) is a novel heptacyclic spiroindolinone alkaloid consisting of a 4,5-dihydro- $1 H$-pyrrolo[3,2,1-ij]quinoline2,6-dione ring system and an amide-bridged cyclopenta[f]indolizidine ring system connected via a spiro-carbon atom. Compound $\mathbf{1}$ is structurally related to the family of prenylated indole alkaloids containing the bicyclo[2.2.2] diazaoctane ring system as a core structure. ${ }^{7}$ This family of natural products, including the brevianamides, paraherquamides, stephacidin, asperparalines, marcfortines, notoamides, malbrancheamides, avrainvillamide and sclerotiamide, has been reported mainly from various fungi of the genera Aspergillus and Penicillium, ${ }^{10}$ and several biological activities, including 
a

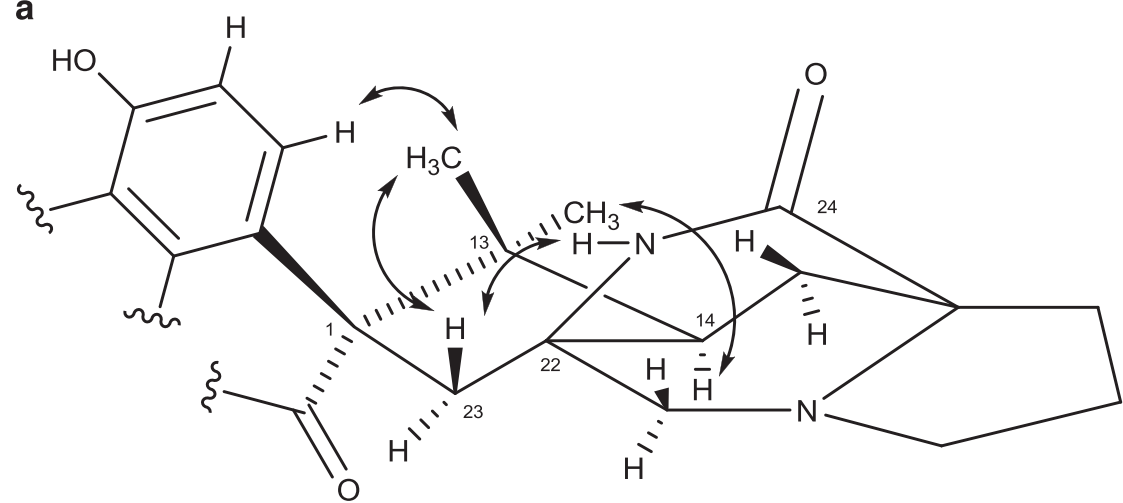

b

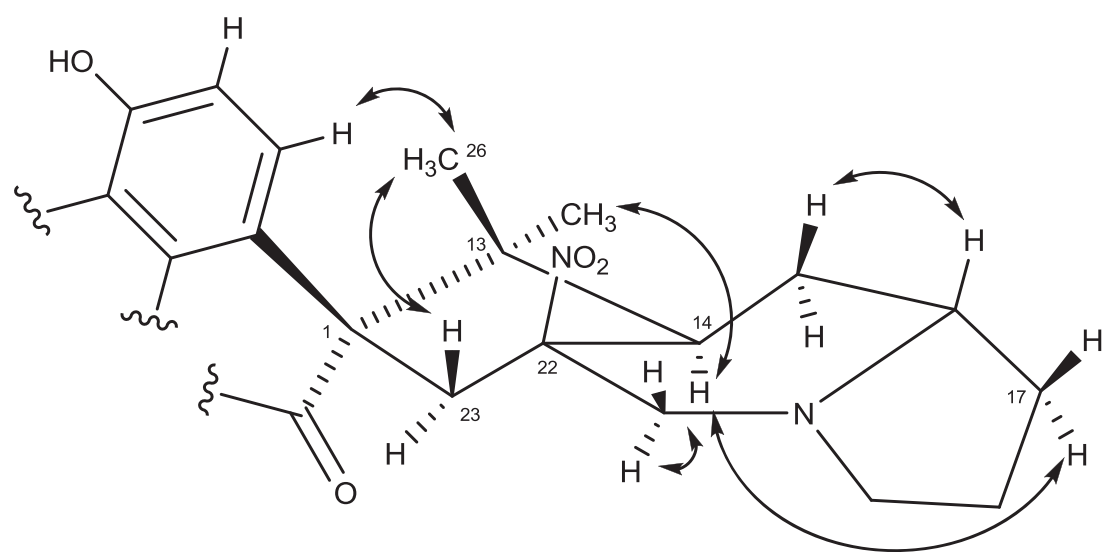

Figure 2 Key NOESY correlations (a) for the amide-bridged cyclopenta[f]indolizidine portion of cycloexpansamine A (1), and (b) for the cyclopenta[f] indolizidine portion of cycloexpansamine B (2).

insecticidal, antitumor, anthelmintic, calmodulin inhibitory and antibacterial properties, are displayed by members of this family. ${ }^{7}$ Because of their complex structures and diverse bioactivities, studies of synthetic and biosynthetic pathways leading to these alkaloids has become an area of significant interest. ${ }^{13-16}$ In line with this, it is noteworthy that cycloexpansamine A (1) represents a rare example of prenylated indole alkaloids with the anti-relative configuration between the $\mathrm{C} 13-\mathrm{C} 14$ and $\mathrm{C} 16-\mathrm{N} 24$ bonds in the [2.2.2] diazaoctane core system. ${ }^{7,17}$ In addition, cycloexpansamine A (1) is the only member of this family that contains a 4,5 -dihydro- $1 H$-pyrrolo [3,2,1-ij] quinoline-2,6-dione ring system derived from condensation of the indole ring and a prenyl group.

Cycloexpansamine B (2) is closely related to cyclopiamines $\mathrm{A}^{11}$ and $\mathrm{B},{ }^{11,12}$ which are the only precedent secondary metabolites possessing a 4,5-dihydro- $1 H$-pyrrolo[3, 2, 1-ij] quinoline-2,6-dione ring system. The relative configurations of cyclopiamine $\mathrm{B}$ was originally established by single-crystal X-ray crystallography. ${ }^{11}$ In the course of the structure elucidation of cyclopiamine B (a diasteromer of cyclopiamine A), the desmethylated analog of cyclopiamine B, which possesses the same planar structure as that of $\mathbf{2}$, was prepared by treatment with aluminum chloride in nitrobenzene. ${ }^{18}$ Recently, $\mathrm{O}$-desmethylcyclopiamine B has been asymmetrically synthesized in the course of total synthesis of cyclopiamine B possessing absolute configuration of $1 R, 14 R, 16 R$ and $22 S{ }^{9}{ }^{9}$ The structure of $\mathbf{2}$ differs from $\mathrm{O}$-desmethylcyclopiamine B only in the configurations at stereogenic centers. To confirm the diastereomeric relationship between $O$-desmethylcyclopiamine B and 2, the NMR data of 2 in $\mathrm{CDCl}_{3}$ were compared with those reported for the asymmetrically synthesized $O$-desmethylcyclopiamine B in the same solvent. Although a comprehensive comparison was hampered by the limited availability of 2 , clear differences in proton shift values for prominent peaks, including the aromatic and methyl proton signals were observed (2: aromatic ${ }^{1} \mathrm{H}$ signals at $\delta_{\mathrm{H}} 7.41(\mathrm{br} \mathrm{d}, J=7.0,1 \mathrm{H})$ and 6.57 (br d, $J=7.0 \mathrm{~Hz}, 1 \mathrm{H})$; methyl ${ }^{1} \mathrm{H}$ signals at $\delta_{\mathrm{H}} 1.77(\mathrm{~s}, 3 \mathrm{H}), 1.46$ $(\mathrm{s}, 3 \mathrm{H}), 0.97(\mathrm{~s}, 3 \mathrm{H})$ and $0.80(\mathrm{~s}, 3 \mathrm{H})$; O-desmethylcyclopiamine $\mathrm{B}$ : aromatic ${ }^{1} \mathrm{H}$ signals at $\delta_{\mathrm{H}} 7.20(\mathrm{br} \mathrm{d}, J=8.3,1 \mathrm{H})$ and $6.48(\mathrm{br} \mathrm{d}$, $J=8.3 \mathrm{~Hz}, 1 \mathrm{H})$; methyl ${ }^{1} \mathrm{H}$ signals at $\delta_{\mathrm{H}} 1.73(\mathrm{~s}, 3 \mathrm{H}), 1.41(\mathrm{~s}, 3 \mathrm{H}), 1.03$ $(\mathrm{s}, 3 \mathrm{H})$ and $0.89(\mathrm{~s}, 3 \mathrm{H}))$. These data support the conclusion that 2 is a diastereomer of asymmetrically synthesized $\mathrm{O}$-desmethylcyclopiamine $\mathrm{B}$, possessing inverted configurations at $\mathrm{C}-1, \mathrm{C}-14$ and $\mathrm{C}-16$ compared to the respective positions in $\mathrm{O}$-desmethylcyclopiamine $\mathrm{B}$. It is also noteworthy that encountering fungal metabolites possessing a nitro group is unusual. Cyclopiamines A and B from Penicillium cyclopium, ${ }^{11}$ cyclopiamin B from Aspergillus caespitosus ${ }^{12}$ and citrinalins A, $\mathrm{B}^{13}$ and 17-hydroxycitrinalin $\mathrm{B}^{18}$ from $P$. citrinum are rare examples of precedent fungal metabolites bearing such functionality. It has been suggested that cyclopiamines and citrinalins biogenetically arise from a bicyclo[2.2.2] diazaoctane precursor via hydrolysis of the amide bridge, decarboxylation and amino group oxidation to the nitro group. However, such a precursor was unknown until a recent report of the co-isolation of nitro group containing 17-hydroxycitrinalin B and a bicyclo[2, 2, 2] diazaoctane-containing precursor. ${ }^{18}$ Thus, the isolation of cycloexpansamines A and B is be an additional example of co-isolation of biogenetically related metabolites, and this supports the existence of a common bicyclo[2.2.2] diazaoctane-containing biogenetic precursor to nitro group containing prenylated indole alkaloids. 
Table 2 NMR spectroscopic data for cycloexpansamine B (2) in pyridine- $d_{5}$

\begin{tabular}{|c|c|c|c|c|}
\hline No. & $\delta C^{\mathrm{a}}$ & $\begin{array}{l}\delta_{H}, \text { mult. } \\
(\mathrm{J} \text { in } \mathrm{Hz})^{\mathrm{b}}\end{array}$ & Key NOESY ${ }^{\mathrm{c}}$ & $H M B C(H \rightarrow C \#)$ \\
\hline 1 & 61.8 & - & - & \\
\hline 2 & 182.3 & - & - & - \\
\hline 4 & 57.0 & - & - & - \\
\hline 5 & 51.1 & \multirow{2}{*}{$\begin{array}{l}2.66, d(16.5) \\
2.99, d(16.5)\end{array}$} & - & \multirow{2}{*}{$\begin{array}{c}4,6,7,24 \\
4,6,24,25\end{array}$} \\
\hline 6 & 197.0 & & 二 & \\
\hline 7 & 104.7 & - & - & - \\
\hline 8 & 159.7 & - & - & - \\
\hline 9 & 108.9 & $6.68, \mathrm{~d}(8.3)$ & - & $7,8,11$ \\
\hline 10 & 134.1 & $7.28, \mathrm{~d}(8.3)$ & $\mathrm{H}-23 \beta, \mathrm{H}-26$ & $1,8,12$ \\
\hline 11 & 118.6 & - & - & - \\
\hline $\begin{array}{l}12 \\
13\end{array}$ & $\begin{array}{r}147.5 \\
47.4\end{array}$ & $\overline{-}$ & - & - \\
\hline 14 & 47.5 & $3.15, \mathrm{~m}$ & $\begin{array}{c}\mathrm{H}-15 \alpha, \mathrm{H}-17 \alpha, \mathrm{H}-21 \alpha, \\
\mathrm{H}-23 \alpha, \mathrm{H}-27\end{array}$ & 15,21 \\
\hline 15 & 22.4 & (ß) 2.95, m & $\mathrm{H}-16, \mathrm{H}-26$ & \multirow{2}{*}{$\begin{array}{c}13,16,17,22 \\
13,16,22 \\
13,15,21\end{array}$} \\
\hline 16 & 58.8 & $\begin{array}{c}3.16, \mathrm{dd}(9.9 \\
4.3)\end{array}$ & $\begin{array}{c}H-14,-15 \beta \\
H-15 \beta\end{array}$ & \\
\hline 17 & 27.5 & (a) $1.69, \mathrm{~m}$ & $\mathrm{H}-14, \mathrm{H}-15 \alpha$ & \multirow{2}{*}{$\begin{array}{l}18 \\
18 \\
17\end{array}$} \\
\hline \multirow[t]{2}{*}{18} & 22.6 & ( $\beta) 1.81, \mathrm{~m}$ & $\mathrm{H}-19 \beta$ & \\
\hline & & 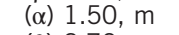 & $H-19 \alpha$ & $\overline{16}$ \\
\hline 19 & 54.3 & $\begin{array}{l}\text { ( } \beta \text { ) 2.70, m } \\
(\alpha) 2.65, m\end{array}$ & $\begin{array}{c}\mathrm{H}-18 \beta, \mathrm{H}-21 \beta \\
\mathrm{H}-18 \alpha\end{array}$ & \multirow{2}{*}{$\begin{array}{c}16 \\
18,21 \\
14,16,22\end{array}$} \\
\hline \multirow[t]{2}{*}{21} & 60.5 & $\begin{array}{l}(\beta) 3.22, d \\
(11.0)\end{array}$ & $\mathrm{H}-19 \beta$ & \\
\hline & & $\begin{array}{c}(\alpha) 2.98, \mathrm{~d} \\
(11.0)\end{array}$ & $\mathrm{H}-14$ & 16,19 \\
\hline $\begin{array}{l}22 \\
23\end{array}$ & $\begin{array}{l}95.9 \\
43.7\end{array}$ & (B) $308 \mathrm{~d}$ & $\overline{H-26}$ & \multirow{3}{*}{$\begin{array}{c}1,2, \overline{11}, 13 \\
22 \\
1,2,13,22\end{array}$} \\
\hline \multirow{2}{*}{23} & & $\begin{array}{l}\text { (ק) } 3.08, \mathrm{a} \\
(15.8)\end{array}$ & $\mathrm{H}-26$ & \\
\hline & & $\begin{array}{l}(\alpha) 2.67, d \\
(15.8)\end{array}$ & $\mathrm{H}-14$ & \\
\hline 24 & 23.7 & $1.39, \mathrm{~s}$ & - & $4,5,25$ \\
\hline 25 & 26.5 & $1.74, \mathrm{~s}$ & $-\overline{1} 0$ & $4,5,24$ \\
\hline 26 & 22.9 & $0.94, \mathrm{~s}$ & $\mathrm{H}-10, \mathrm{H}-15 \beta, \mathrm{H}-23 \beta$ & $1,13,27$ \\
\hline 27 & 23.4 & $0.96, \mathrm{~s}$ & $\mathrm{H}-14, \mathrm{H}-15 \alpha$ & $1,14,26$ \\
\hline
\end{tabular}

Recorded at $150 \mathrm{MHz}$

becorded at $600 \mathrm{MHz}$

'Recorded at $600 \mathrm{MHz}$.

Cycloexpansamine A (1) moderately inhibited the activity of protein tyrosine phosphatase $1 \mathrm{~B},{ }^{19,20}$ a promising and a validated therapeutic target to effectively treat type 2 diabetes mellitus and obesity, showing an $\mathrm{IC}_{50}$ value of $27.6 \mu \mathrm{M}$, while 2 was inactive against protein tyrosine phosphatase $1 \mathrm{~B}$ at levels up to $100 \mu \mathrm{M}$.

\section{ACKNOWLEDGEMENTS}

We acknowledge the financial support by grants from the Global R\&D Center (GRDC, NRF-2010-00719) programs of the National Research Foundation of Korea (NRF) funded by the Ministry of Science, ICT and Future Planning of Korea (MSIFP).

1 Fenical, W. \& Jensen, P. R. Developing a new resource for drug discovery: marine actinomycete bacteria. Nat. Chem. Biol. 2, 666-673 (2006).

2 Bugni, T. S. \& Ireland, C. M. Marine-derived fungi: a chemically and biologically diverse group of microorganisms. Nat. Prod. Rep. 21, 143-163 (2004).

3 Saleem, M. et al. Marine natural products of fungal origin. Nat. Prod. Rep. 24 1142-1152 (2007)

4 Rateb, M. E. \& Ebel, R. Secondary metabolites of fungi from marine habitats. Nat. Prod Rep. 28, 290-334 (2011).

5 Lee, D.-S. et al. Penicillinolide A: a new anti-Inflammatory metabolite from the marine fungus Penicillium sp. SF-5292. Mar. Drugs 11, 4510-4526 (2013).

6 Onodera, H. et al. (Kyowa Hakko Kirin Co., Ltd.). Proliferation promoting agent for neural stem cells. US2011/0020931 A1 (2011).

7 Greshock, T. J. et al. Isolation, structure elucidation, and biomimetic total synthesis of versicolamide $\mathrm{B}$, and the isolation of antipodal (-)-stephacidin A and (+)-notoamide B from Aspergillus versicolor NRRL 35600. Angew. Chem. Int. Ed. Engl. 47, 3573-3577 (2008)

8 Takayama, H. et al. Stereochemical studies on the Uncaria alkaloid, 3-oxo-7-hydroxy3,7-secorhynchophylline: the absolute configuration of 3-hydroxyoxindole derivatives. Tetrahedron 55, 6841-6846 (1999).

9 Mugishima, T. et al. Absolute stereochemistry of citrinadins A and B from marinederived fungus. J. Org. Chem. 70, 9430-9435 (2005).

10 Tsukamoto, S. et al. Notoamides F-K, prenylated indole alkaloids isolated from a marine-derived Aspergillus sp. J. Nat. Prod. 71, 2064-2067 (2008).

11 Bond, R. F., Boeyens, J. C. A., Holzapfel, C. W. \& Steyn, P. S. Cyclopiamines A and B novel oxindole metabolites of Penicillium cyclopium westling. J. Chem. Soc. Perkin Trans. 1, 1751-1761 (1979)

12 Steyn, P. S., Vleggaar, R. \& Rabie, C. J. Alkaloids from Aspergillus caespitosus Phytochemistry 20, 538-539 (1981).

13 Pimenta, E. F. et al. Use of experimental design for the optimization of the production of new secondary metabolites by two Penicillium species. J. Nat. Prod. 73, 1821-1832 (2010)

14 Kato, H. et al. Notoamides A-D: Prenylated indole alkaloids isolated from a marine-derived fungus, Aspergillus sp. Angew. Chem. Int. Ed. Engl. 46, 2254-2256 (2007)

15 Grubbs, A. W., Artman, G. D. III, Tsukamoto, S. \& Williams, R. M. A. Concise total synthesis of the notoamides C and D. Angew. Chem. Int. Ed. Engl. 46, 2257-2261 (2007)

16 Tsukamoto, S. et al. Isolation of antipodal (-)-versicolamide B and notoamides L-N from a marine-derived Aspergillus sp. Org. Lett. 11, 1297-1300 (2009).

17 Cai, S. et al. Isolation and photoinduced conversion of 6-epi-stephacidins from Aspergillus taichungensis. Org. Lett. 15, 2168-2171 (2013).

18 Mercado-Marin, E. V. et al. Total synthesis and isolation of citrinalin and cyclopiamine congeners. Nature 509, 318-324 (2014).

19 Vintonyak, V. V., Antonchick, A. P., Rauh, D. \& Waldmann, H. The therapeutic potential of phosphatase inhibitors. Curr. Opin. Chem. Biol. 13, 272-283 (2009).

20 Johnson, T. O., Ermolieff, J. \& Jirousek, M. R. Protein tyrosine phosphatase 1B inhibitors for diabetes. Nat. Rev. Drug. Discov. 1, 696-709 (2002).

Supplementary Information accompanies the paper on The Journal of Antibiotics website (http://www.nature.com/ja) 